survey of cancer in the area, but detailed geographical results have not to our knowledge been published or made publicly available. A retrospective study of hospital or pathology records, or both, is required but might be difficult to carry out in view of the quality of record keeping in the past.

Our report highlights the need to establish a permanent cancer registry for this area of France available to researchers. This is all the more important as a nuclear power station began to operate $16 \mathrm{~km}$ away in December 1985. et de la Recherche Médicale (Service Commun 8) for providing the mortality data.

1 Forman D, Cook-Mozaffari P, Darby S, et al. Cancer near nuclear installations. Nature 1987;329:499-505.

2 Gardner MJ. Review of reported increases of childhood cancer rates in the vicinity of nuclear installations in the UK. Fournal of the Royal Statistical Society [Series A] 1989;152:307-85.

3 Gardner MJ, Winter PD. Mortality in Cumberland during 1959-78 with reference to cancer in young people around Windscale. Lancet 1984;i:216-7. 4 Heasman MA, Kemp IW, Urquhart JD, Black R. Childhood leukaemia in northern Scotland. Lancet 1986; ; 266.

5 Guéguéniat P, Auffret JP, Baron Y. Evolution of gamma artificial radioactivity in coastal sediments of the English Channel during the years 1976, 1977 and 1978. Oceanologica Acta 1979;2:165-80.

(Accepted 13 December 1989)

\title{
Effectiveness of using end tidal carbon dioxide concentration to monitor cardiopulmonary resuscitation
}

\section{Higgins, $M$ Hayes, W Denman, D J Wilkinson}

\section{Department of \\ Anaesthesia, \\ St Bartholomew's Hospital, \\ London EC1A 7BE \\ D Higgins, FCANAES, registrar \\ M Hayes, FCANAES, registrar \\ W Denman, MB, registrar \\ D J Wilkinson, FCANAES, \\ consultant}

Correspondence to:

Dr Wilkinson.

BrMed f 1990;300:58
End tidal carbon dioxide concentration indicates both correct tracheal intubation' and effective cardiac compressions during cardiopulmonary resuscitation. Its application has been limited by the cost and practicality of providing infrared analysers or mass spectrometers at all sites where resuscitation may be attempted. We report the use of a cheap pocket sized detector that allows immediate recognition and correction of oesophageal intubation and ineffective cardiac compression.

\section{Methods and results}

The end tidal carbon dioxide detector (FEF; Fenem) is a portable device that does not require a power supply. It has an internal volume of $38 \mathrm{ml}$, a flow resistance $<3 \mathrm{~cm}$ water at $60 \mathrm{l} / \mathrm{min}$, and weighs $<30 \mathrm{~g}$. An easily visible colour change shows the variation in carbon dioxide concentration during inspiration and expiration.

We used the detector in 30 varied resuscitations at this hospital. At the site of resuscitation the patient's trachea was intubated and the detector inserted between the tracheal tube and the breathing system. Each patient was then ventilated with six breaths of $100 \%$ oxygen and the colour of the indicator during full expiration was matched to one of the three colour ranges illustrated on the detector (table).

The detector indicated a concentration of $<0.3 \%$ in

Colour shown by end tidal carbon dioxide detector after six breaths of pure oxygen in 30 patients being resuscitated

\begin{tabular}{|c|c|c|c|}
\hline Colour & $\begin{array}{l}\text { End tidal } \\
\text { carbon dioxide } \\
\text { indicated } \\
(\%)\end{array}$ & $\begin{array}{c}\text { No of } \\
\text { patients }\end{array}$ & Events noted \\
\hline Purple & $<0.3$ & 3 & $\begin{array}{l}\text { Endotracheal tube misplaced in } \\
\text { two patients (oesophageal } \\
\text { intubation). Ineffective } \\
\text { precordial compression in third } \\
\text { case }\end{array}$ \\
\hline Light purple & $0 \cdot 5-1$ & 8 & $\begin{array}{l}\text { Two patients successfully } \\
\text { resuscitated; in both cases return } \\
\text { of spontaneous circulation was } \\
\text { associated with change in colour } \\
\text { to yellow }\end{array}$ \\
\hline Yellow & $>2$ & 19 & $\begin{array}{l}\text { Spontaneous circulation had } \\
\text { returned at time of assessment in } \\
\text { six patients; resuscitation } \\
\text { attempts failed in } 13 \text { patients }\end{array}$ \\
\hline
\end{tabular}

three patients. In two of these the tube had been placed in the oesophagus; when the tube was correctly positioned under direct vision the detector changed colour to yellow, indicating a concentration of $>2 \%$. In the third patient correct placement of the tube was confirmed by direct vision and auscultation. The cardiac compression was immediately altered and the detector changed colour to light purple, indicating a more effective circulation.

In two other patients the end tidal carbon dioxide concentration spontaneously increased without any apparent alteration in the efficiency of cardiac compression or ventilation. The increase was associated with a return of spontaneous circulation; during inspiration the detector returned to a purple colour $(<0.3 \%$ carbon dioxide), indicating that the effect was not due to the patient rebreathing expired gas.

\section{Comment}

The detector successfully differentiated between oesophageal and tracheal intubation in every case. It is important to note that making a clinical decision before administering at least six breaths through the detector can yield false results. If the stomach is distended with air before intubation carbon dioxide concentrations may be as high as $4.5 \%$. Ventilation with six breaths of pure oxygen will, however, reduce the carbon dioxide concentration in the oesophagus to nearly zero. ${ }^{3}$

We identified one case in which ineffective cardiac compression produced inadequate pulmonary blood flow. Smalhout and Kalenda reported a similar case, which they attributed to chest compressions being less vigorous than necessary because the person performing resuscitation was tired. ${ }^{4} \mathrm{~A}$ spontaneous increase in end tidal carbon dioxide concentration was first linked with the return of a patient's circulation by Garnett et al. ${ }^{5}$ Our study confirmed this finding and showed that precordial compression need not be interrupted to confirm that spontaneous circulation has been restored. We believe that the end tidal carbon dioxide detector provides a valuable aid in managing cardiopulmonary resuscitation and should be available at all sites where such resuscitations are attempted.

We thank EME-Tricomed, Brighton, for providing the detectors used in this trial and Miss Michele Langley for secretarial help.

1 Birmingham PK, Cheney FW, Ward RJ. Esophageal intubation: a review of detection techniques. Anesth Analg 1986;65:886-91

Falk JL, Rackow EC, Weil MH. End-tidal carbon dioxide concentration durin cardiopulmonary resuscitation. $N$ Engl f Med 1989;318:607-11.

3 Linko K, Paloheims M, Tammisto T. Capnography for detection of accidental oesophageal intubation. Acta Anaesthesiol Scand 1983;27:199-202.

Smalhout B, Kalenda Z. An atlas of capnography. Vol 1. Zeist, Netherlands: Kerckebosch, 1975:28-33.

5 Garnett AR, Ornato SP, Gonzalez ER, et al. End-tidal carbon dioxide monitoring during cardiopulmonary resuscitation. $\mathcal{F} A M A$ 1987;257:512-5.

(Accepted 21 November 1989) 